\title{
Antibodies against Staphylococcus aureus DNase in goat serum
}

Staphylococcus aureus is widely distributed among animals both as a normal inhabitant and as a pathogenic agent. The presence of antibodies against the DNase of $S$. aureus (antiDNases) has been demonstrated in sera from different animal species, including cattle (Sandvik 1974, Gudding 1980). However, very little information seems to be available on staphylococcal antibodies in caprine sera. In the present study, serum antiDNases were determined in samples from this species and related to some epidemiological determinants.

The material included sera from 719 lactating goats, and 29 kids aged from 5-13 weeks, as well as 15 sera from neonatal goat kids taken before first suckling. The animals originated from 10 different Norwegian herds. The age distribution of the lactating goats in 9 herds (Herd 1-9) was almost identical, most animals being in their first or second lactation. In the last herd (Herd 10), most of the goats were in the second or fourth lactation.

In one herd (Herd 1), udder half milk samples were collected and subjected to both bacteriological analysis and examination of somatic cell content by the California Mastitis Test. Samples for the detection of antiDNases in serum were taken from the goats in this herd 15 days after the milk samples had been collected. An agar diffusion method employing microtitre plates was used for monitoring the level of antiDNases in the sera (Høie \& Gudding 1990). The DNase in the test was produced by a $S$.aureus strain $\left(\mathrm{NVH}^{*}\right.$ 3610) isolated from a case of caprine mastitis. The titre was defined as $\log _{10}$ of the reciprocal value of the highest serum dilution preventing any change of colour of the toluidine blue DNA agar (TDA) from blue to pink.

AntiDNase titres equal to or greater than 0.3 , were found in altogether 676 out of 719 (94\%) lactating goats, and in 16 out of 29 (55\%) kids. AntiDNases were not detected in any of the 15 sera from neonatal goat kids taken before first suckling.

The antiDNase titres in lactating goats from the different herds and for all the kids are presented in Table 1 . The individual herd mean titre varied from 0.88 to 2.03 .

* Culture collection at the Department of Microbiology and Immunology, Norwegian College of Veterinary Medicine.

Table 1. AntiDNase titres (means, standard error of the mean (SE)) for lactating goats from 10 herds (A) and 29 kids originating from different herds (B).

\begin{tabular}{rccc}
\hline \multirow{2}{*}{$\begin{array}{c}\text { Herd } \\
\text { no. }\end{array}$} & $\begin{array}{c}\text { Number of } \\
\text { animals } \\
\text { examined }\end{array}$ & \multicolumn{2}{c}{ AntiDNase titres } \\
\cline { 3 - 4 } A. 1 & 111 & 1.76 & 0.06 \\
2 & 76 & 1.86 & 0.08 \\
3 & 90 & 1.33 & 0.10 \\
4 & 68 & 1.05 & 0.09 \\
5 & 66 & 1.77 & 0.08 \\
6 & 87 & 0.88 & 0.07 \\
7 & 76 & 1.61 & 0.07 \\
8 & 35 & 1.65 & 0.13 \\
9 & 65 & 1.51 & 0.09 \\
10 & 45 & 2.03 & 0.08 \\
\hline B. Kids & 29 & 0.58 & 0.12 \\
\hline
\end{tabular}


The highest mean titre was demonstrated in the herd with the highest average age (Herd 10).

In Herd 1 the mean titre for 14 animals with $S$. aureus mastitis was $2.29 \pm 0.11$ (SE), while the corresponding value for 53 animals without mastitis was $1.80 \pm 0.08$. The difference was significant ( $p<0.005$, $t$-test). The age distributions for these 2 groups were almost identical. In the same herd 36 yearlings had a mean titre of $1.51 \pm 0.10$ while 29 goats, aged from 3 to 4 years, had a mean titre of $1.83 \pm 0.11$. The difference was statistically significant ( $\mathrm{p}<0.025, \mathrm{t}$-test).

The high prevalence of goats with antiDNases shows that $S$. aureus is widely distributed in goat herds. Titre values increasing with age suggest a more or less continuous antigen exposure. However, the herd-to-herd variation in titre levels might reflect great variations in exposure to staphylococcal antigens.

The demonstration of high antiDNase titres in goats with a previous $S$. aureus mastitis is consistent with results from similar studies in the cow (Gudding 1980).
Steinar Høie,

Department of Microbiology and Immunology, Norwegian College of Veterinary Medicine, Oslo and National Veterinary Institute, Oslo, Norway.

Gudmund Holstad,

Department of Microbiology and Immunology, Norwegian College of Veterinary Medicine, Oslo, Norway.

Trond Slettbakk,

State Veterinary Laboratory for

Northern Norway, Harstad, Norway.

\section{References}

Gudding $R$ : Antibodies against staphylococcal and streptococcal nucleases in bovine blood serum and milk. Acta vet. scand. 1980, 21, 242-255.

Hoie $S$, Gudding $R$ : A method for monitoring antibodies against staphylococcal DNases. Acta vet. scand. 1990, 31, 223-226.

Sandvik, $O$ : The occurrence of antibodies against staphylococcal deoxyribonucleases in blood sera from different species. Acta vet. scand. $1974,15,631-635$.

(Received March 18; accepted October 3, 1989).

Reprints may be requested from: Steinar Høie, National Veterinary Institute, P. O. Box 8156, N-0033 Oslo 1, Norway. 